\title{
(GIGA)bYte
}

DATA RELEASE

\section{Annotation of glycolysis, gluconeogenesis, and trehaloneogenesis pathways provide insight into carbohydrate metabolism in the Asian citrus psyllid}

Blessy Tamayo ${ }^{1}$, Kyle Kercher ${ }^{1}$, Chad Vosburg ${ }^{1}$, Crissy Massimino ${ }^{1}$, Margaryta R. Jernigan ${ }^{1}$, Denisse L. Hasan ${ }^{1}$, Douglas Harper ${ }^{1}$, Anuja Mathew ${ }^{1}$, Samuel Adkins ${ }^{1}$, Teresa Shippy ${ }^{2}$, Prashant S. Hosmani ${ }^{3}$, Mirella Flores-Gonzalez ${ }^{3}$, Naftali Panitz ${ }^{3}$, Lukas A. Mueller ${ }^{3}$, Wayne B. Hunter ${ }^{4}$, Joshua B. Benoit ${ }^{5}$, Susan J. Brown' ${ }^{2}$, Tom D'Elia ${ }^{1}$ and Surya Saha ${ }^{3,6, *}$

1 Indian River State College, Fort Pierce, FL 34981, USA

2 Division of Biology, Kansas State University, Manhattan, KS 66506, USA

3 Boyce Thompson Institute Ithaca, NY 14853, USA

4 US Department of Agriculture-Agricultural Research Service (USDA-ARS), US Horticultural Research Laboratory, Fort Pierce, FL 34945, USA

5 Department of Biological Sciences, University of Cincinnati, Cincinnati, OH 45221, USA

6 Animal and Comparative Biomedical Sciences, University of Arizona, Tucson, AZ 85721, USA

Submitted: $\quad 12$ October 2021

Accepted: $\quad 11$ February 2022

Published: $\quad 16$ February 2022

* Corresponding author. E-mail: suryasaha@cornell.edu

Published by GigaScience Press.

Preprint submitted at https: //doi.org/10.1101/2021.10.11.463922

Included in the series: Asian citrus psyllid community annotation (https://doi.org/10.46471/GIGABYTE SERIES_0001)

This is an Open Access article distributed under the terms of the Creative Commons Attribution License (https://creativecommons. org/licenses/by/4.0/), which permits unrestricted reuse, distribution, and reproduction in any medium, provided the original work is properly cited.

Gigabyte, 2022, 1-19

\section{ABSTRACT}

Citrus greening disease is caused by the pathogen Candidatus Liberibacter asiaticus and transmitted by the Asian citrus psyllid, Diaphorina citri. No curative treatment or significant prevention mechanism exists for this disease, which causes economic losses from reduced citrus production. A high-quality genome of $D$. citri is being manually annotated to provide accurate gene models to identify novel control targets and increase understanding of this pest. Here, we annotated $25 \mathrm{D}$. citri genes involved in glycolysis and gluconeogenesis, and seven in trehaloneogenesis. Comparative analysis showed that glycolysis genes in D. citri are highly conserved but copy numbers vary. Analysis of expression levels revealed upregulation of several enzymes in the glycolysis pathway in the thorax, consistent with the primary use of glucose by thoracic flight muscles. Manually annotating these core metabolic pathways provides accurate genomic foundation for developing gene-targeting therapeutics to control $D$. citri.

Subjects Genetics and Genomics, Animal Genetics, Bioinformatics

\section{DATA DESCRIPTION}

\section{Background}

Huanglongbing (HLB), or citrus greening disease, is the biggest global threat to the citrus industry throughout the world [1]. The phloem-limited bacterial pathogen Candidatus Liberibacter asiaticus (CLas) is the causative agent of HLB. Upon infection of a citrus tree, 
HLB causes development of small, bitter fruits, loss of tree vigor, fruit drop, and ultimately tree decline and death [1-4]. This bacterium is transmitted by the psyllid vector, Diaphorina citri (NCBI:txid121845), when feeding on citrus [5, 6]. Pesticide application to eliminate D. citri has been unsuccessful and no cure for HLB exists [7, 8]. To develop new psyllid control strategies, the International Psyllid Genome Consortium was established in 2009 [9] to provide the genome, transcriptome resources, and an official gene set of $D$. citri [10,11]. A recent, nearly complete genome with significantly improved gene accuracy has been generated, providing a valuable dataset for the establishment of gene-targeted strategies to suppress psyllid populations (opensource: Diaci_v3.0, www.citrusgreening.org [12]; USDA-NIFA grant 2015-70016-23028). As part of this genome project, we manually annotated genes in critical pathways to provide the quality gene models required to design molecular therapeutics such as RNA interference (RNAi) [13-21], antisense oligonucleotides (ASO) [16, 20, 22] and gene editing (CRISPR) [23, 24]. Here, we examined D. citri orthologs associated with the critical metabolic pathways glycolysis, gluconeogenesis, and trehaloneogenesis.

\section{Context}

A community-driven annotation strategy was used to identify and characterize the genes encoding enzymes involved in glycolysis, gluconeogenesis, and trehaloneogenesis (Figure 1).

Glycolysis is vital metabolic pathway in core energy processing reactions, and provides a source of metabolites for other biochemical processes. Insects utilize much glucose in flight muscles in the thorax [28]. Accordingly, the activities of glycolytic enzymes are increased in insect flight muscle compared with vertebrate muscle tissue [29]. Gluconeogenesis is essential in insects to maintain sugar homeostasis and serves as the initial step towards generating glucose disaccharide, also known as trehalose. Trehalose is the main circulating sugar in the insect hemolymph [30-32]. In trehaloneogenesis, glucose-6-phosphate is converted into trehalose by trehalose-6-phosphate synthase (TPS). Trehalase enzymes then degrade trehalose into two glucose molecules [33]. Genes involved in psyllid glycolysis, gluconeogenesis, and trehaloneogenesis have been targeted by several RNAi studies (Table 1) as a promising avenue for psyllid population suppression. In particular, one proof of concept experiment targeting trehalase led to the release of the first RNAi patent to control psyllid populations [49]. RNAi, as a biopesticide, and strategies for delivery and applications to target insect pests and viral pathogens have been thoroughly reviewed [50-54].

\section{METHODS}

The $D$. citri genome was manually annotated through a collaborative community-driven strategy [11] with an undergraduate focus that allows specific students to focus on main gene sets [55]. Orthologous protein sequences for the glycolysis, gluconeogenesis, and trehaloneogenesis pathways were obtained from the National Center for Biotechnology Information (NCBI) protein database [56] and were used to BLAST the D. citri MCOT (Maker (RRID:SCR_005309), Cufflinks (RRID:SCR_014597), Oases (RRID:SCR_011896), and Trinity (RRID:SCR_013048)) protein database to find predicted protein models [25]. MCOT predicted protein models were used to search the $D$. citri genomes (versions 2.0 and 3.0) [55]. Regions of high sequence identity were manually curated in Apollo v2.1.0 (RRID:SCR_001936) using 


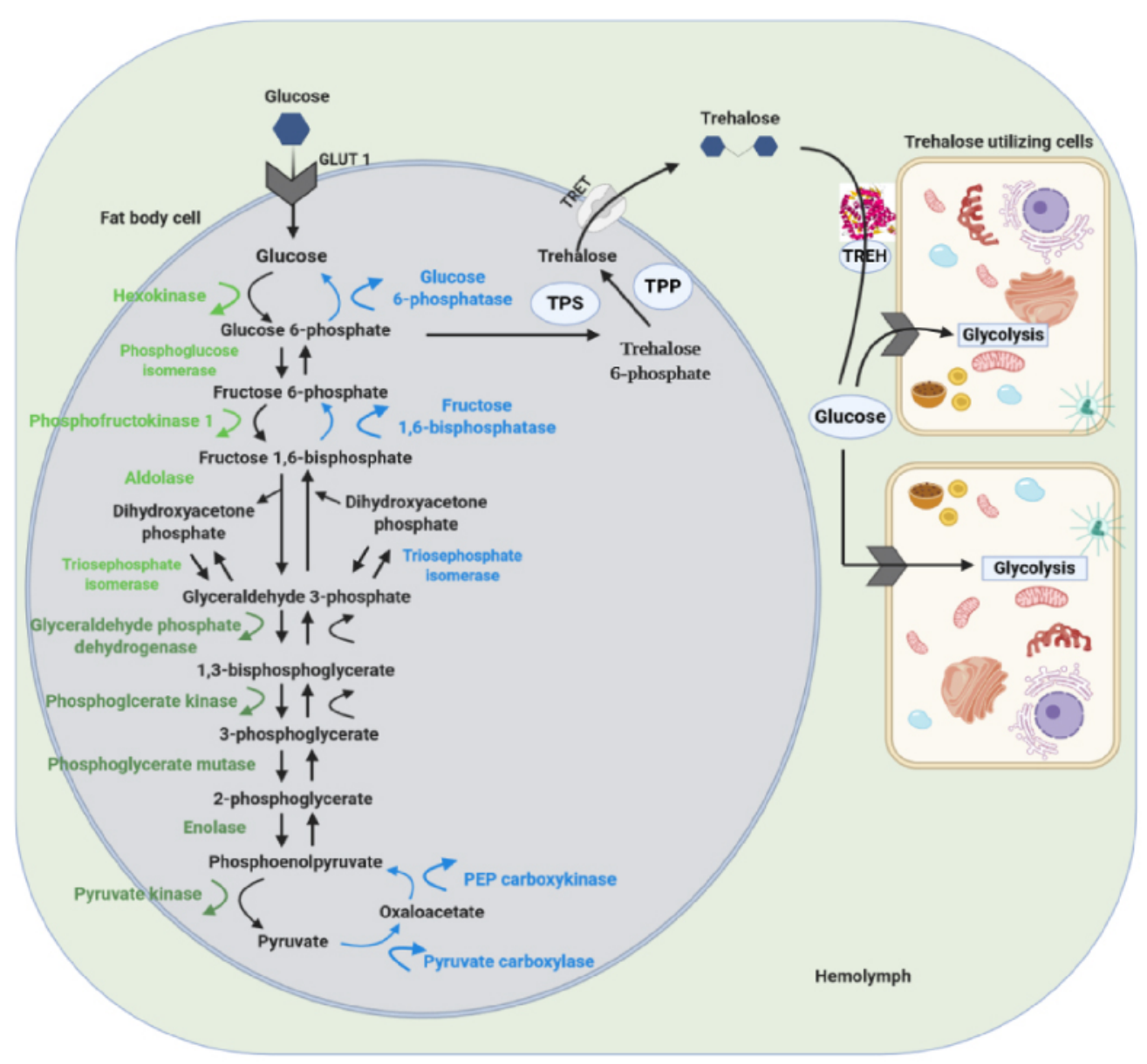

Figure 1. Overview of the glycolysis, gluconeogenesis, and trehaloneogenesis pathways. The pathway image shows the enzymes that produce and utilize glucose and trehalose in insects [25]. The glycolysis pathway comprises 10 enzymes that convert glucose into pyruvate as the final product. These are divided into the energy investment phase (light green) and the energy production phase (dark green). The gluconeogenesis pathway comprises eight enzymes (blue), with three being unique to the pathway that bypasses the irreversible reactions in glycolysis to convert non-carbohydrate molecules into glucose. The trehaloneogenesis pathway comprises three enzymes: trehalose-6-phosphate synthase (TPS), trehalose-6-phosphate phosphatase (TPP), and trehalase (TREH), as well as trehalose transporters (TRET) and glucose transporters (GLUT1). Image adapted from a diagram in [26] and created with BioRender.com [27].

de novo transcriptome, MCOT gene predictions, RNA-seq, Iso-seq, and ortholog data to support and evaluate gene structure (Table 2). The curated gene models were compared with other orthologous sequences, such as hemipterans, available through NCBI for accuracy. A more detailed description of the annotation workflow is available (Figure 2) [58].

Neighbor-joining phylogenetic trees of the annotated hexokinase gene models in D. citri and orthologous sequences were created with MEGA v7 (RRID:SCR_000667) using the MUSCLE (RRID:SCR_011812) multiple sequence alignment with $p$-distance for determining branch length and 1,000 bootstrap replicates [59].

Expression levels of the carbohydrate metabolism genes throughout different life stages (egg, nymph, and adult) in CLas infected and uninfected $D$. citri insects were collected from 


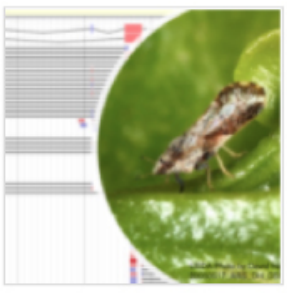

Dec 16, 2020
Annotating genes in Diaphorina citri genome version 3

Teresa Shippy ${ }^{1}$, S Miller $^{2}$, C Massimino $^{3}, \mathrm{C}$ Vosburg [Indian

River State Colleae ${ }^{4}$. PS Hosmani ${ }^{5}$. M Flores-Gonzalez ${ }^{5}$. LA..

${ }^{1}$ Kansas State University, ${ }^{2}$ Kansas State University, Allen

Countv Communitv Colleae. ${ }^{3}$ Indian River State Colleae....

Figure 2. Protocol for D. citri genome community curation [58]. https://www.protocols.io/widgets/doi?uri=dx.doi. org/10.17504/protocols.io.bniimcce

\begin{tabular}{|c|c|c|c|}
\hline Genes & Organism & RNAi outcome & Reference \\
\hline Hexokinase (HK) Tc-HexA1 & Tribolium castaneum & $\begin{array}{c}\text { HexA1 role in glucose metabolism is essential during oogenesis and } \\
\text { embryogenesis }\end{array}$ & [34] \\
\hline Aldolase UAS-Aldolase-RNAi & Drosophila melanogaster & $\begin{array}{l}\text { Knockdown in Drosophila neurons and glia resulted in reduced } \\
\text { lifespan; essential in glia for neuronal maintenance }\end{array}$ & [35] \\
\hline Enolase a-enolase & Nilaparvata lugens & $\begin{array}{l}\text { Knockdown reduced egg production, offspring and hatching rate; } \\
\text { mortality of adults was unaffected }\end{array}$ & [36] \\
\hline Pyruvate kinase $(P Y K) ~ N l P Y K$ & Nilaparvata lugens & $\begin{array}{l}\text { RNAi treatment including triazophos and } d s N l P Y K \text { led to reduced } \\
\text { ovarian protein content, ovarian and fat body soluble sugar contents, } \\
\text { and fecundity }\end{array}$ & [37] \\
\hline $\begin{array}{l}\text { Phosphoenolpyruvate carboxykinase } \\
\text { (PEPCK) }\end{array}$ & Drosophila melanogaster & $\begin{array}{l}\text { Knockdown of two PEPCK mutant isoforms led to reduced circulating } \\
\text { glycerol levels and reduced triglyceride levels in pepck1 mutant flies }\end{array}$ & [38] \\
\hline Trehalose-6-phosphate synthase (TPS) & Diaphorina citri & $\begin{array}{l}\text { Knockdown of the Trehalose- 6-phosphate synthase gene using RNA } \\
\text { interference inhibits synthesis of trehalose and increases lethality rate } \\
\text { in Asian citrus psyllid }\end{array}$ & [39] \\
\hline $\begin{array}{l}\text { Trehalose phosphate synthase (TPS) } \\
\text { NITPS }\end{array}$ & Nilaparvata lugens & $\begin{array}{c}\text { Feeding } N \text {. lugens larvae with NlTPS dsRNA led to disrupted expression } \\
\text { and lethality }\end{array}$ & [40] \\
\hline Trehalose-6- phosphate synthases & Nilaparvata lugens & $\begin{array}{l}\text { Silencing of two TPS genes can lead to increased molting deformities } \\
\text { and mortality rates leading to misregulation of chitin metabolism genes }\end{array}$ & [41] \\
\hline chitin synthase* & Diaphorina citri & Silencing of the chitin synthase gene is lethal to the Asian citrus psyllid & [42] \\
\hline Five trehalase genes & Tribolium castaneum & Regulates gene expression of the chitin biosynthesis pathway & [43] \\
\hline Trehalase genes (TRE) & Nilaparvata lugens & Wing bud chitin metabolism and its development & [44] \\
\hline Trehalase & Nilaparvata lugens & Regulating the chitin metabolism pathway & [45] \\
\hline Muscle protein $20 \ddagger$ & Diaphorina citri & Increases mortality to the Asian citrus psyllid & [46] \\
\hline Sucrose hydrolase $\ddagger$ & Diaphorina citri & Causes nymph mortality and disturbs adult osmotic homeostasis & [47] \\
\hline
\end{tabular}

the Citrus Greening Expression Network (CGEN) [25] and visualized using Excel (RRID:SCR_016137) and the pheatmap package in R (RRID:SCR:_016418).

\section{DATA VALIDATION AND QUALITY CONTROL}

There are four phases of the carbohydrate metabolism pathways in D. citri: the energy investment phase of glycolysis, the energy production phase of glycolysis, gluconeogenesis, and trehaloneogenesis. Enzymes involved in the breakdown and synthesis of glucose and trehalose were annotated in version 3.0 of the $D$. citri genome [57]. The following genes in the energy investment phase: hexokinase (HK), phosphoglucose isomerase (PGI), phosphofructokinase (PFK), fructose-bisphosphate aldolase (aldolase), triosephosphate isomerase (TPI), and in the energy production phase: glyceraldehyde phosphate dehydrogenase (GAPDH), phosphoglycerate kinase (PGK), phosphoglycerate mutase (PGAM), 


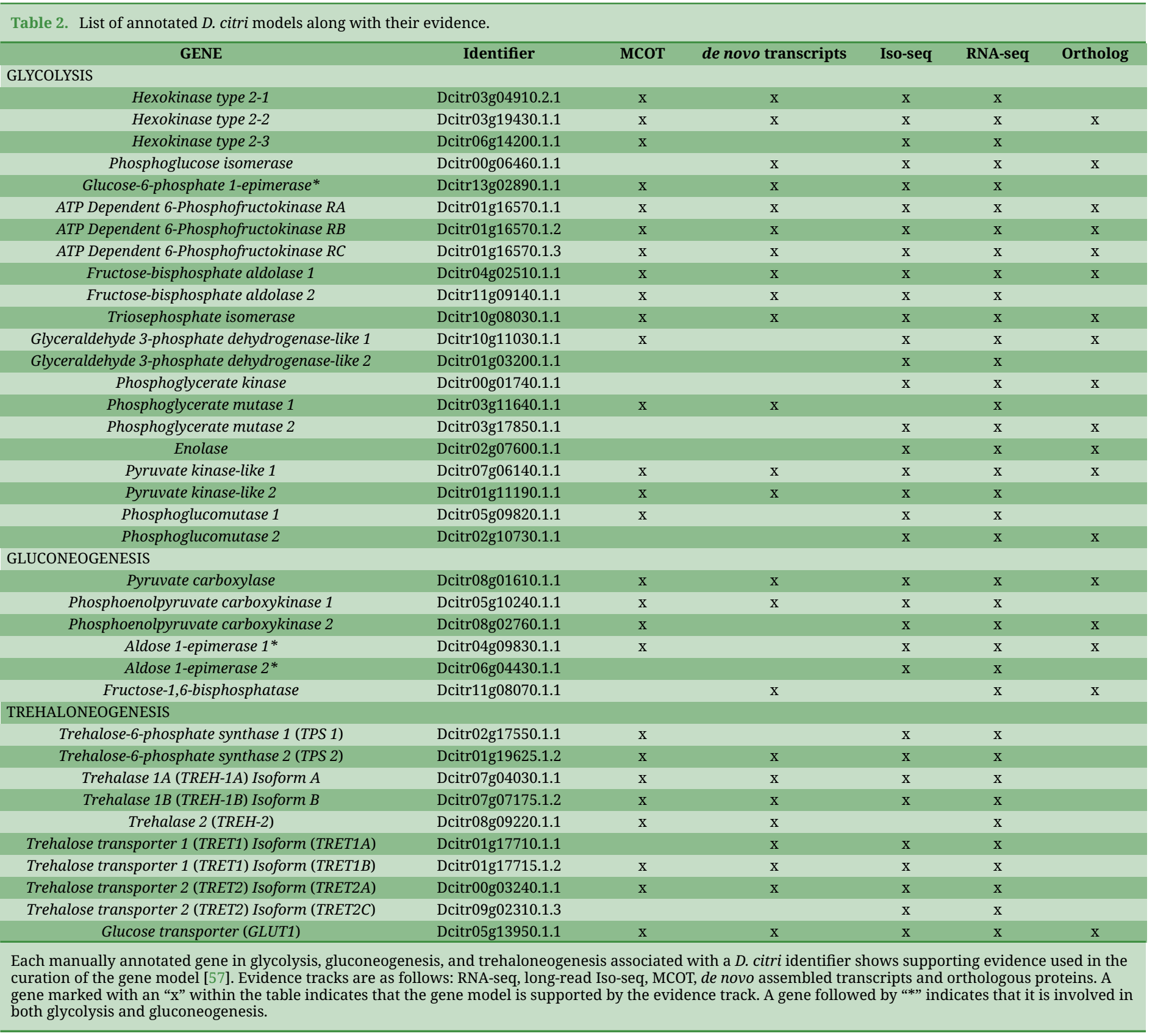

enolase, and pyruvate kinase ( $P Y K)$ were annotated. The annotated genes for gluconeogenesis are pyruvate carboxylase $(P C)$, phosphoenolpyruvate carboxykinase (PEPCK), and fructose 1,6-bisphosphatase (FBPase). In trehaloneogenesis, trehalose transporter 1 (TRET1) and 2 (TRET2), glucose transporter 1 (GLUT1), and two gene models of both trehalose-6-phosphate synthase (TPS) and trehalase (TREH) were annotated. Gene expression datasets in CGEN were analyzed for potential differences, as expression patterns can provide insight into potential RNAi target candidates for molecular therapeutics (Table 1). 


\begin{tabular}{|c|c|c|c|c|c|c|c|}
\hline Protein & $\begin{array}{c}\text { Drosophila } \\
\text { melanogaster }\end{array}$ & $\begin{array}{c}\text { Tribolium } \\
\text { castaneum }\end{array}$ & Apis mellifera & $\begin{array}{c}\text { Acyrthosiphon } \\
\text { pisum }\end{array}$ & $\begin{array}{c}\text { Drosophila } \\
\text { pseudoobscura }\end{array}$ & $\begin{array}{l}\text { Halyomorpha } \\
\text { halys }\end{array}$ & $\begin{array}{c}\text { Nilaparvata } \\
\text { lugens }\end{array}$ \\
\hline \multirow[t]{2}{*}{ Hex-A } & NP_001259384.1 & XP_008201714.1 & XP_006557646.1 & XP_003242238.1 & XP_001355083.1 & & XP_022204875.1 \\
\hline & & XP_970645.1 & & XP_001952412.1 & & & \\
\hline Hex-type 1 & & & & & & XP_014282249.1 & XP_022184109.1 \\
\hline Hex-type 2 & & & & & & XP_014282721.1 & \\
\hline Hex-C & NP_524674.1 & & & & XP_001360104.2 & & \\
\hline Hex-t1 & NP_788744.1 & & & & XP_001359146.2 & & \\
\hline Hex-t2 & NP_733151.2 & & & & XP_002137641.2 & & \\
\hline
\end{tabular}

Orthologous sequences from related insects and information about conserved motifs or domains were used to determine the final annotation. We used proteins from Drosophila melanogaster (Dm) [60], Tribolium castaneum (Tc) [61], Apis mellifera (Am) [62], Acyrthosiphon pisum (Ap) [63], Nilaparvata lugens (Nl) [64, 65], and Halyomorpha halys (Hh) [66]. Accession numbers are provided in Table 3.

\section{Energy investment phase of glycolysis}

$H K$ catalyzes the first step in glycolysis, utilizing adenosine triphosphate (ATP) to phosphorylate glucose, creating glucose-6-phosphate. Most insects have multiple $H K$ genes and three copies of $H K$ are present in the D. citri genome (Figure 3, Tables 2 and 4). In insect flight muscles, $H K$ activity is inhibited by its product, glucose-6-phosphate, to initiate flight muscle activity [69]. Drosophila melanogaster has four duplicated $H K$ genes, with $H e x-A$ being the most conserved and essential flight muscle $H K$ isozyme among Drosophila species [70, 71]. For Diasporina citri, one of the copies of HK type 2-2 (Dcitr03g19430.1.1) showed moderate expression in the male and female thorax. In contrast, another copy $H K$ type 2-3 (Dcitr06g14200.1.1), was highly expressed in the adult gut and midgut compared with $H K$ type 2-2 and its overall expression (Figure 4). PGI catalyzes the interconversion of glucose-6-phosphate and fructose-6-phosphate in the second step of glycolysis. Consistent with the gene copy number of PGI for orthologs in other insects, such as D. melanogaster, Apis mellifera, Acyrthosiphon pisum, and Tribolium castaneum, a single copy of PGI (Dcitr00g06460.1.1) was found. Expression for PGI is high in the male and female thorax (Figure 4).

$P F K$, which catalyzes the phosphorylation of fructose-6-phosphate using ATP to generate fructose-1,6-bisphosphate and adenosine diphosphate (ADP), is the key regulatory enzyme controlling glycolysis in insects, as it catalyzes a rate-determining reaction [76, 77]. One copy of PFK (Dcitr01g16570.1.1) was found and annotated in D. citri (Table 4). Aldolase catalyzes the fourth step, the reversible aldol cleavage of fructose-1,6-bisphosphate to form two trioses, glyceraldehyde-3-phosphate (GAP) and dihydroxyacetone phosphate (DHAP). Although most insects have a single copy of this gene, two well supported copies were found in D. citri (Table 4). One of the aldolase annotated copies, fructose-bisphosphate aldolase 1, (Dcitr04g02510.1.1) appears to have moderate expression in the male abdomen and terminal abdomen, and highest expression in the adult whole body (Figure 4). TPI catalyzes the fifth step, the reversible interconversion of DHAP and GAP. TPI is also important to sustain DHAP to maintain insect flight muscle activity [78]. D. citri contains a single copy of this gene (Dcitr10g08030.1.1), which is consistent with other insects (Table 4). 


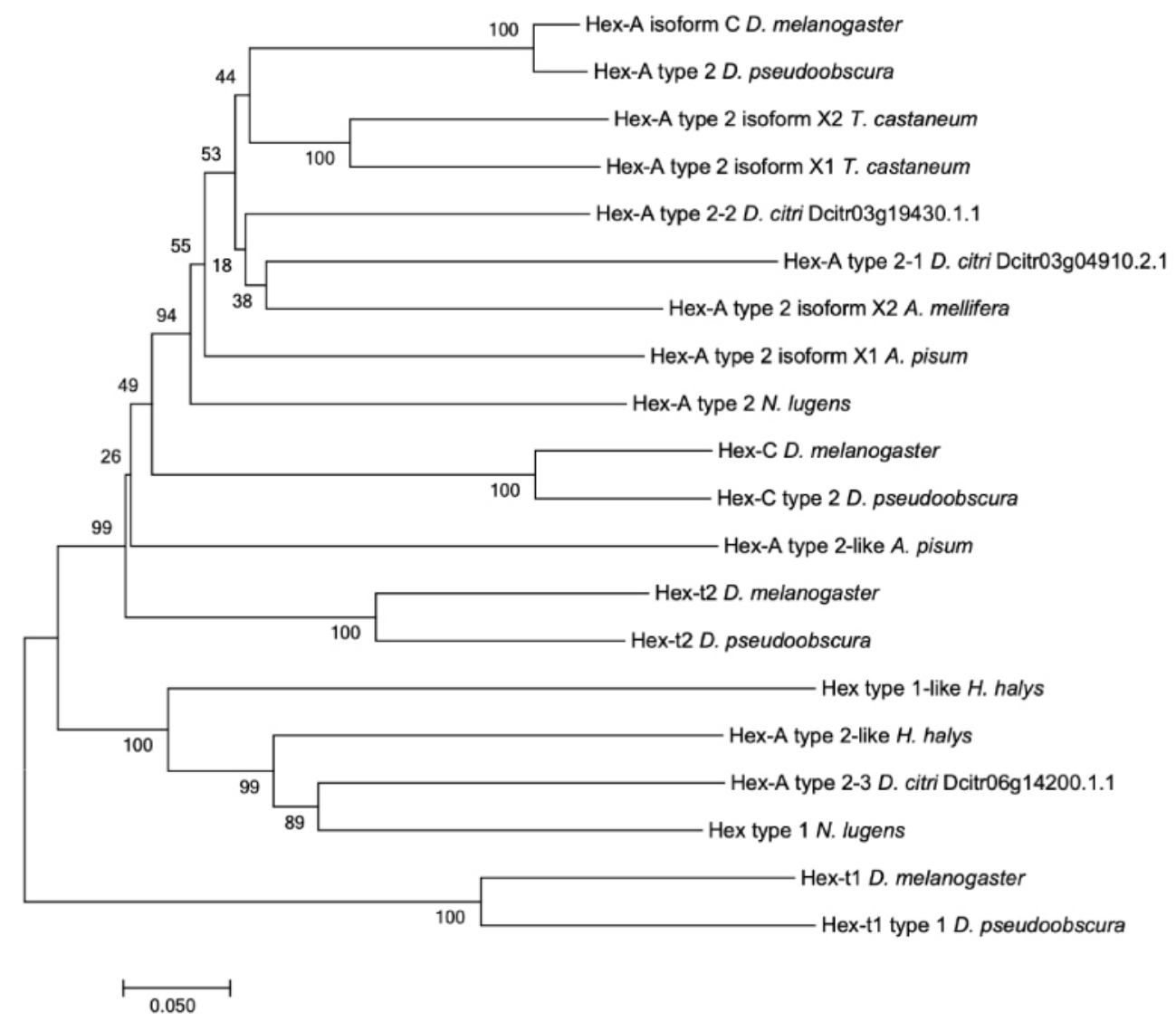

Figure 3. Phylogenetic analysis of hexokinase $(H K)$. Hexokinase amino acid sequence of $D$. citri compared with sequences from other insects. MUSCLE multiple sequence alignments of $H K$ in $D$. citri and orthologs were performed using MEGA7 and neighbor-joining phylogenetic trees were constructed with $p$-distance for determining evolutionary distance and 1000 bootstrapping replicates [59]. Accession numbers for the orthologous sequences used in phylogenetic analysis are in Table 3.

Expression of several of these genes in the investment phase was high in the male and female thorax, especially in PFK (Dcitr01g16570.1.1), fructose-bisphosphate aldolase 2 (Dcitr11g09140.1.1), and TPI (Dcitr10g08030.1.1) (NCBI BioProject PRJNA448935) (Figure 4 and Table 3 in GigaDB [79]).

\section{Energy production phase of glycolysis}

GAPDH catalyzes the reversible conversion of GAP to 1,3-bisphosphoglycerate during glycolysis. Two GAPDH genes were annotated in $D$. citri and the expression data for the two paralogs show that GAPDH-like 1 (Dcitr10g11030.1.1) has higher expression in the male terminal abdomen and whole body and GAPDH-like 2 (Dcitr01g03200.1.1) has higher expression values overall with a considerable increase in male thorax, female thorax and whole body (NCBI BioProjects PRJNA609978 and PRJNA448935) (Figure 4 and Table 4 in GigaDB [79]).

$P G K$ catalyzes the reversible conversion of 1,3-bisphosphoglycerate to 3-phosphoglycerate (3PG) while generating one molecule of ATP in the seventh step of glycolysis. A single gene was annotated in $D$. citri, and other insects also have single copies 


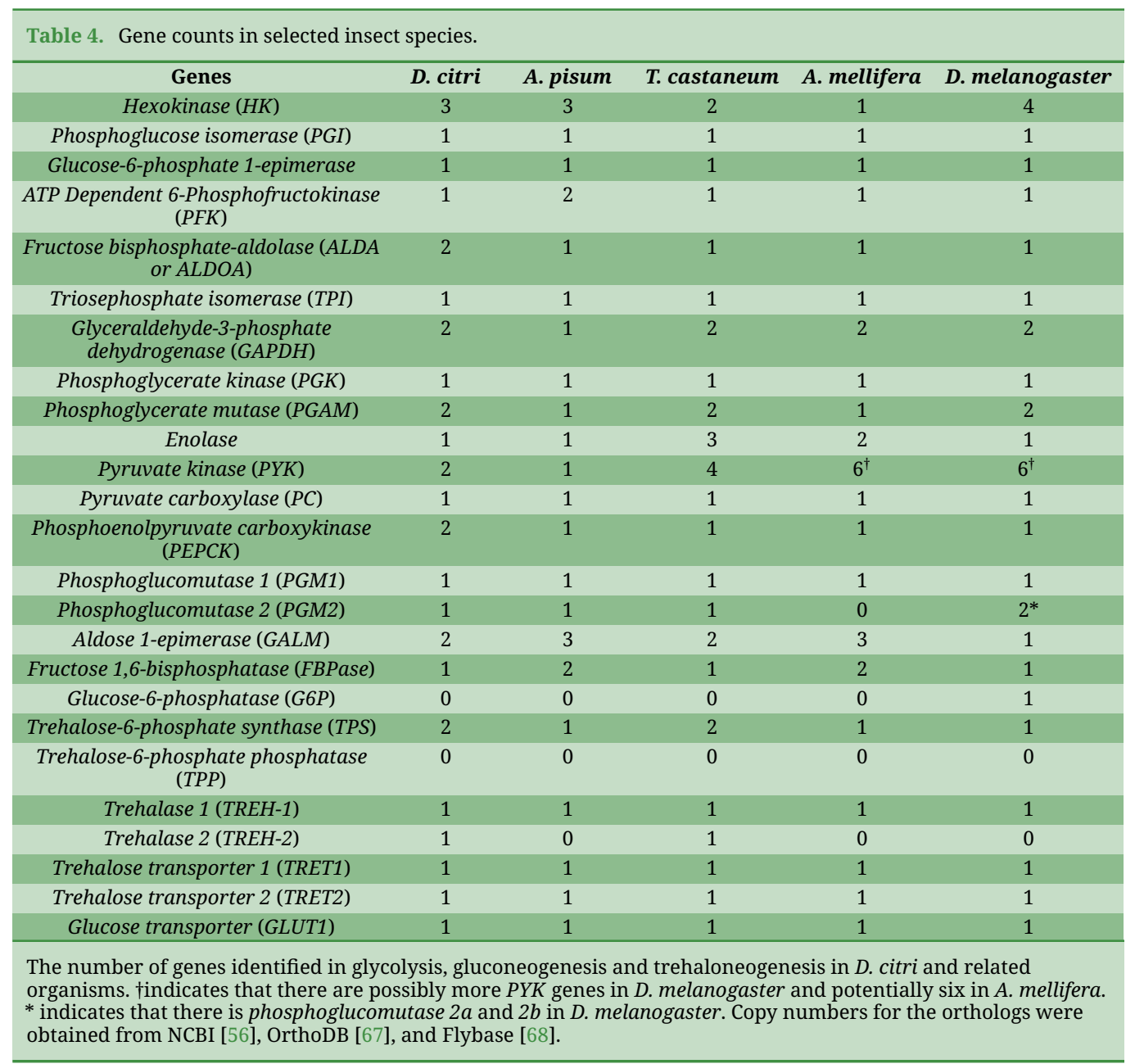

(Table 4). PGAM is an enzyme that converts 3-phosphoglycerate to 2-phosphoglycerate. Members of the $P G A M$ family share a common $P G A M$ domain, and function as either phosphotransferases or phosphohydrolases [80]. Two copies of $P G A M$ were annotated in the $D$. citri genome (Table 4). PGAM 1 (Dcitr03g11640.1.1) has high expression evident in the midgut and the other paralog, PGAM 2 (Dcitr03g17850.1.1) is highly expressed in the whole body (Figure 4).

Enolase catalyzes the conversion of 2-phosphoglycerate to phosphoenolpyruvate in the ninth step of the glycolytic pathway and a single copy was annotated in the $D$. citri genome (Table 4). RNAi knockdown of the a-enolase in Nilaparvata lugens reduced egg production, offspring, and hatching rate; however, mortality of adults was unaffected [80]. Pairwise alignment between the $N$. lugens and $D$. citri sequences reveal the characteristics of the enolase family: a hydrophobic domain (AAVPSGASTGI) in the N-terminal region at position 31-41, a seven amino acid substrate binding pocket (H159, E211, K345, HRS373-375, and K396), a metal-binding site (S38, D246, E295, and D320) and the enolase signature motif (LLLKVNQIGSVTES) [81].

$P Y K$ catalyzes the irreversible transfer of a phosphoryl group from phosphoenolpyruvate to ADP; thus generating pyruvate and a second ATP molecule, the 


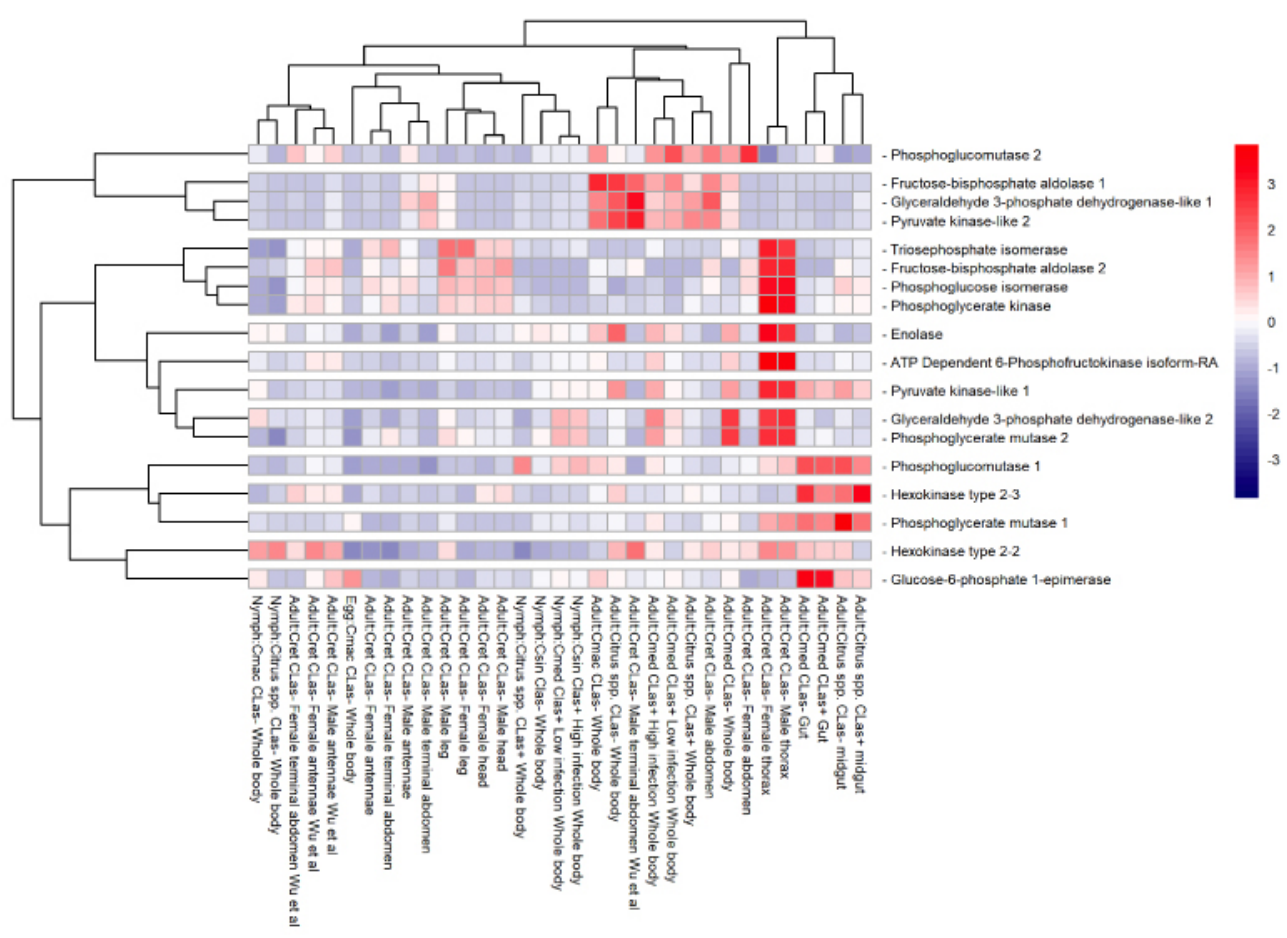

Figure 4. Comparison of RNA-seq datasets of genes involved in glycolysis. The heatmap shows results from $D$. citri reared on various citrus varieties, both infected and uninfected with CLas. Expression values were collected from CGEN [25]. Data in the heatmap show transcripts per million scaled by gene. RNA-seq data are available from NCBI Bioproject's PRJNA609978 and PRJNA448935 and in addition to several published datasets [9, 72-75]. Expression data for HK type 2-1 (Dcitr03g04910.2.1) are not present in the heatmap.

end products of the glycolysis reaction. The copy number of $P Y K$ varies among insects; A. mellifera and D. melanogaster both contain six, and A. gambiae has only one (Table 4). In D. citri, two $P Y K$ genes were characterized and annotated (Table 2). One of the PYK genes (Dcitr07g06140.1.1) is highly expressed in male and female thorax and the other PYK gene (Dcitr01g11190.1.1) has relatively low overall expression with the highest expression in the male terminal abdomen (Figure 4). Expression analysis of the enzymes from this phase of glycolysis in thoracic tissue shows that the highest expression is observed for GAPDH-like 2 and PYK-like 1 and the lowest occurs for both GAPDH-like 1 and PYK-like 2 (Figure 5). In addition, $P G K$ (Dcitr00g01740.1.1) and enolase (Dcitr02g07600.1.1) also have high expression in the male and female thorax and PGAM 2 (Dcitr03g17850.1.1) has high expression in whole body besides the male and female thorax (NCBI BioProject PRJNA609978, NCBI BioProject PRJNA448935) (Figure 4 and Table 4 in GigaDB [79]).

\section{Enzymes of gluconeogenesis}

Gluconeogenesis is the metabolic process to re-generate glucose from non-carbohydrate substrates. It uses four specific enzymes. $P C$ catalyzes the ATP-dependent carboxylation of pyruvate to oxaloacetate. The curated $P C$ model (Dcitr08g01610.1.1) in D. citri shows highest overall expression in the male and female thorax, male and female head, and male and female antenna (Figures 6, 7 and Table 5 in GigaDB [79]).

PEPCK controls cataplerotic flux and converts oxaloacetate from the tricarboxylic acid cycle to form phosphoenolpyruvate (PEP). Two PEPCK genes were annotated and 


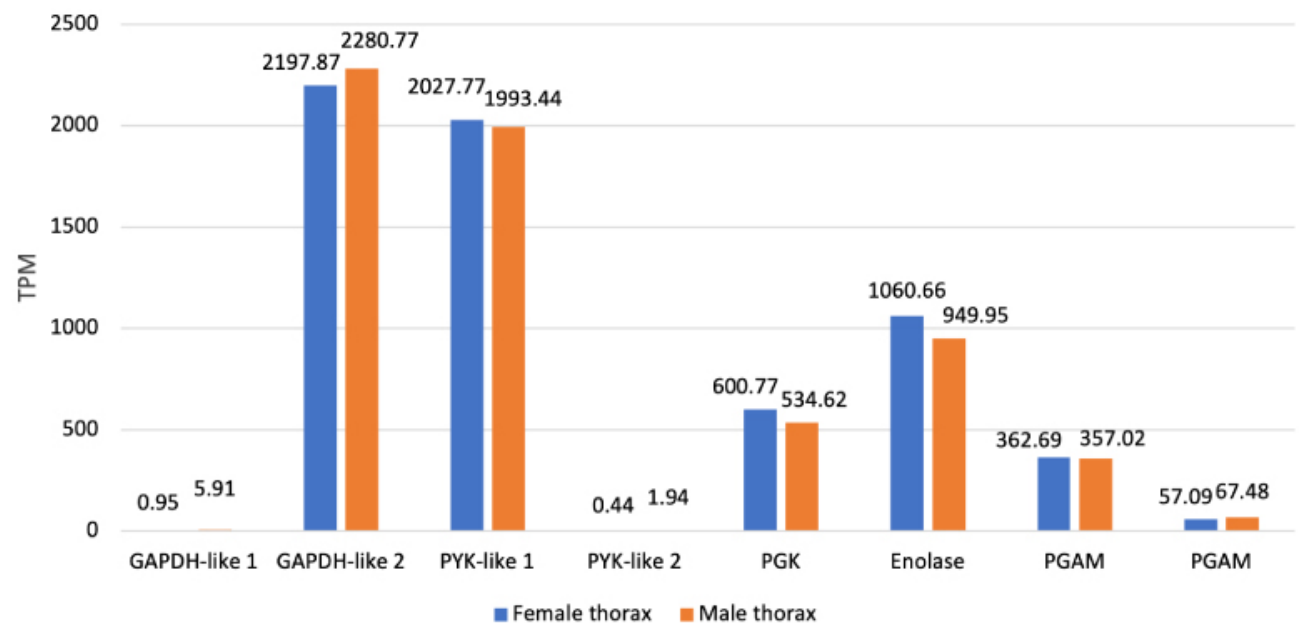

Figure 5. Citrus Greening Expression Network expression data for the enzymes involved in the energy production phase in D. citri. (GAPDH-like 1: Dcitr10g11030.1.1; GAPDH-like 2: Dcitr01g03200.1.1; PYK-like 1: Dcitr07g06140.1.1; PYK-like 2: Dcitr01g11190.1.1; PGK: Dcitr00g01740.1.1; enolase: Dcitr02g07600.1.1; PGAM: Dcitr03g17850.1.1, Dcitr03g11640.1.1 respectively). Values are based on transcripts taken from the thorax of healthy $C$ Las- $D$. citri male and female adults that fed on $C$. reticulata. These experiments had a single replicate. RNA-seq data is available from NCBI BioProject PRJNA448935.

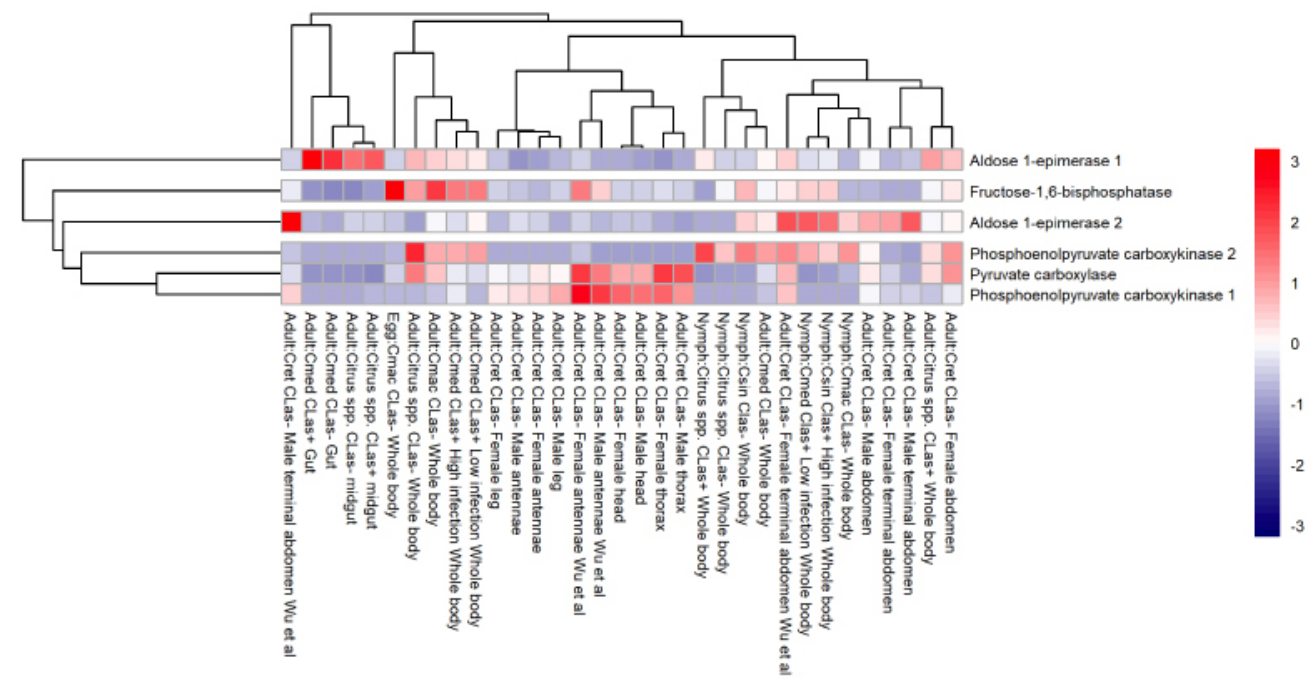

Figure 6. Comparison of RNA-seq datasets of genes involved in gluconeogenesis. The heatmap shows results from $D$. citri reared on various citrus varieties, both infected and uninfected with $C$ Las. Expression values were collected from the Citrus Greening Expression Network [25]. Data in the heatmap show transcripts per million scaled by gene. RNA-seq data are available from NCBI Bioprojects PRJNA609978 and PRJNA448935 and published datasets [72].

characterized in the $D$. citri genome (Table 2). The first PEPCK copy (Dcitr05g10240.1.1) has higher expression in most tissues than all of the other gluconeogenesis genes as is evident in the male and female antenna, male and female thorax, and the male and female head. The highest expression of the second copy of PEPCK (Dcitr08g02760.1.1) is shown in the whole body. FBPase facilitates one of the three bypass reactions in gluconeogenesis, whereby hydrolysis of fructose-1,6-bisphosphate produces fructose-6-phosphate. A single 


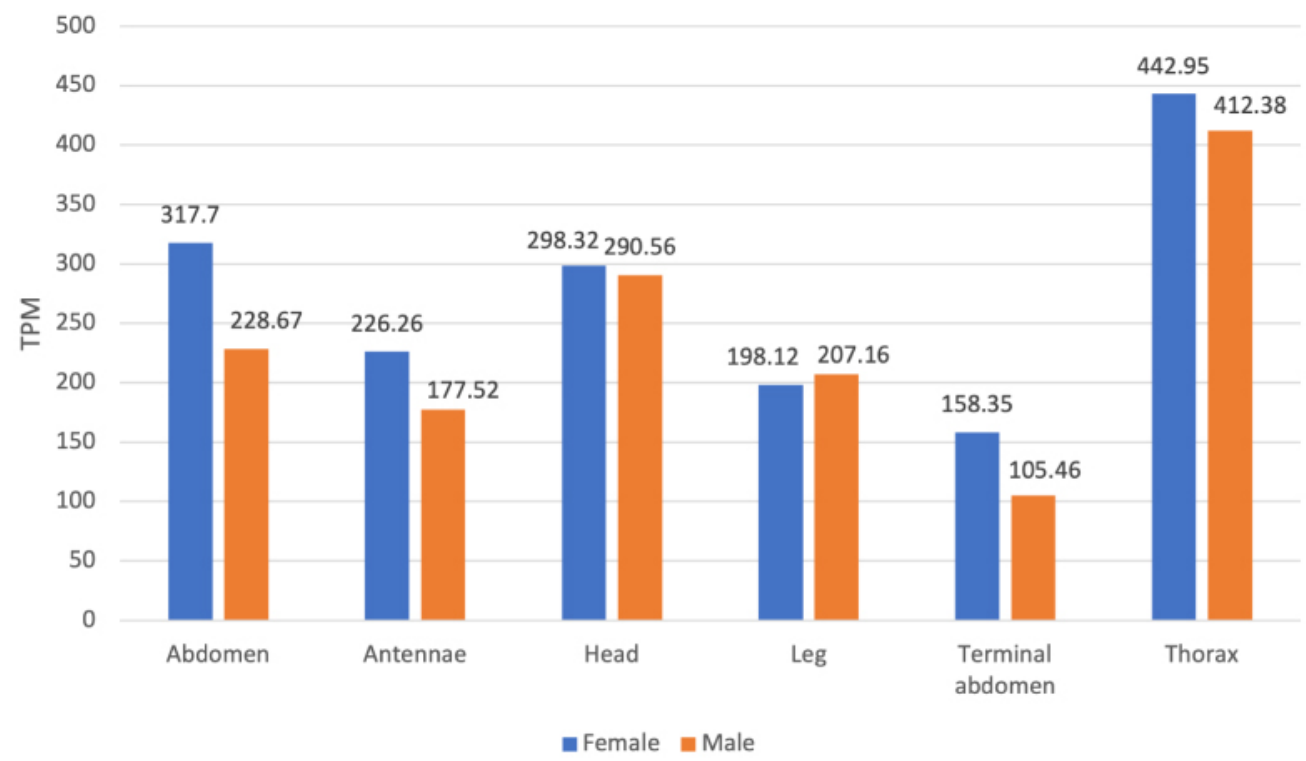

Figure 7. Citrus Greening Expression Network expression data of the enzyme pyruvate carboxylase (Dcitr08g01610.1.1) in D. citri. Values are based on transcripts isolated from various body parts of healthy CLas$D$. citri adults that fed on $C$. reticulata. These experiments had a single replicate. RNA-seq data is available from NCBI BioProject PRJNA448935.

copy of this gene was annotated in $D$. citri, similar to other insects, although two copies are present in the pea aphid, A. pisum, and the honeybee, A. mellifera (Table 2). FBPase (Dcitr11g08070.1.1) shows highest expression in the egg (Figure 5). Glucose-6-phosphatase (G6Pase or G6P), which is specific to gluconeogenesis, catalyzes the conversion of glucose-6-phosphate to glucose [31]. However, this enzyme is not present in most insect species, including $D$. citri. Though present in $N$. lugens, RNAi studies showed that knockdown of G6Pase in $N$. lugens had no effect on the genes involved in trehalose metabolism [82].

\section{Enzymes of trehaloneogenesis}

Trehalose is a non-reducing disaccharide present in many organisms, including yeast, fungi, bacteria, plants and invertebrates. As the main hemolymph sugar in insects, it is found in high concentrations [32, 83]. Trehalose is synthesized from glucose by trehalose-6-phosphate (Tre-6-P), where the mobilization of trehalose to glucose is considered critical for metabolic homeostasis in insect physiology [30]. Synthesis of trehalose occurs in the fat body, when stimulated by neuropeptides from the brain [32]. These peptides decrease the concentration of fructose 2,6-bisphosphate, which strongly activates the glycolytic enzyme $P F K$ and inhibits the gluconeogenic enzyme fructose 1,6-bisphosphatase. Fructose 2,6-bisphosphatase is thus a key metabolic signal in regulating trehalose synthesis in insects. After synthesis, trehalose is transported through the hemolymph and enters cells through trehalose transporters, where it is converted into glucose by trehalase.

Three enzymes are involved in trehaloneogenesis: trehalose-6-phosphate synthase (TPS), trehalose-6-phosphate phosphatase (TPP), and trehalase (TREH) (Figure 1). TPS catalyzes the transfer of glucose from UDP-glucose to G6P forming trehalose 6-phosphate (T6P) and 


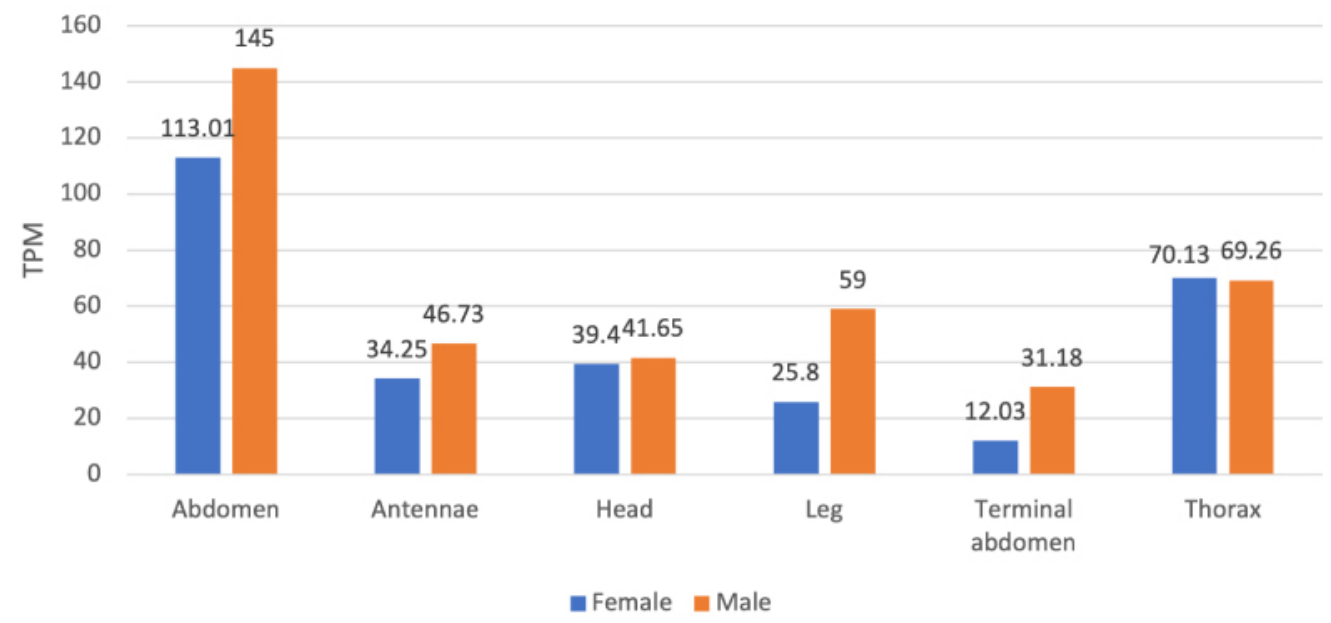

Figure 8. Citrus Greening Expression Network expression data of the enzyme trehalose 6-phosphate synthase (Dcitr02g17550.1.1) in D. citri. Values are based on transcripts expressed in various body parts of healthy $C$ Las- $D$. citri adults that fed on $C$. reticulata. These experiments had a single replicate. RNA-seq data are available from NCBI BioProjects PRJNA448935.

UDP [83]. Targeting a D. citri TPS (DcTPS) gene for RNAi therapeutics revealed that dsRNA-mediated gene-specific silencing strongly reduced expression of DcTPS and survival rate of nymphs, and increased malformation [39]. Two copies of TPS were annotated in the v3 genome of $D$. citri. TPS 1 (Dcitr02g17550.1.1) had the highest expression, found in the CLas+ and CLas- adult midgut, respectively (Figure 8 and Table 6 in GigaDB [79]).

In some organisms, TPP dephosphorylates T6P to trehalose and inorganic phosphate [84]. However, many insects appear to lack this gene, including $D$. citri as it was not found in the v3 genome. Most insects with multiple TPS genes encode proteins with TPS and TPP domains [85, 86]. TPS in Drosophila appears to have the functions of both TPS and TPP [87]. Trehalase (TREH) catalyzes stored trehalose by cleaving it to two glucose molecules. There are two trehalase genes: TREH-1, which encodes a soluble enzyme found in hemolymph, goblet cell cavity and egg homogenates, and TREH-2, which encodes a membrane-bound enzyme found in flight muscle, ovary, spermatophore, midgut, brain and thoracic ganglia [84]. The two curated TREH genes in $D$. citri show different expression in the psyllid. TREH-1A (Dcitr07g04030.1.1) shows high expression in the gut and midgut, and TREH-2 (Dcitr08g09220.1.1) shows moderate expression in the female thorax and male antennae (Figure 9).

TREH is the only enzyme known for the irreversible splitting of trehalose in all insects [84] and D. citri and T. castaneum are the only insects with the second copy, TREH-2 (Table 2).

The two main trehalose transporters are trehalose transporter 1 (TRET1) and trehalose transporter 2 (TRET2), which both transport trehalose to and from cells with TREH. One gene copy for each of these trehalose transporters was annotated in D. citri (Table 2). Expression analysis shows that TRET1 (Dcitr01g17710.1.1) is highly expressed in the gut and TRET2 (Dcitr00g03240.1.1) is moderately expressed in the male abdomen (Figure 9). 


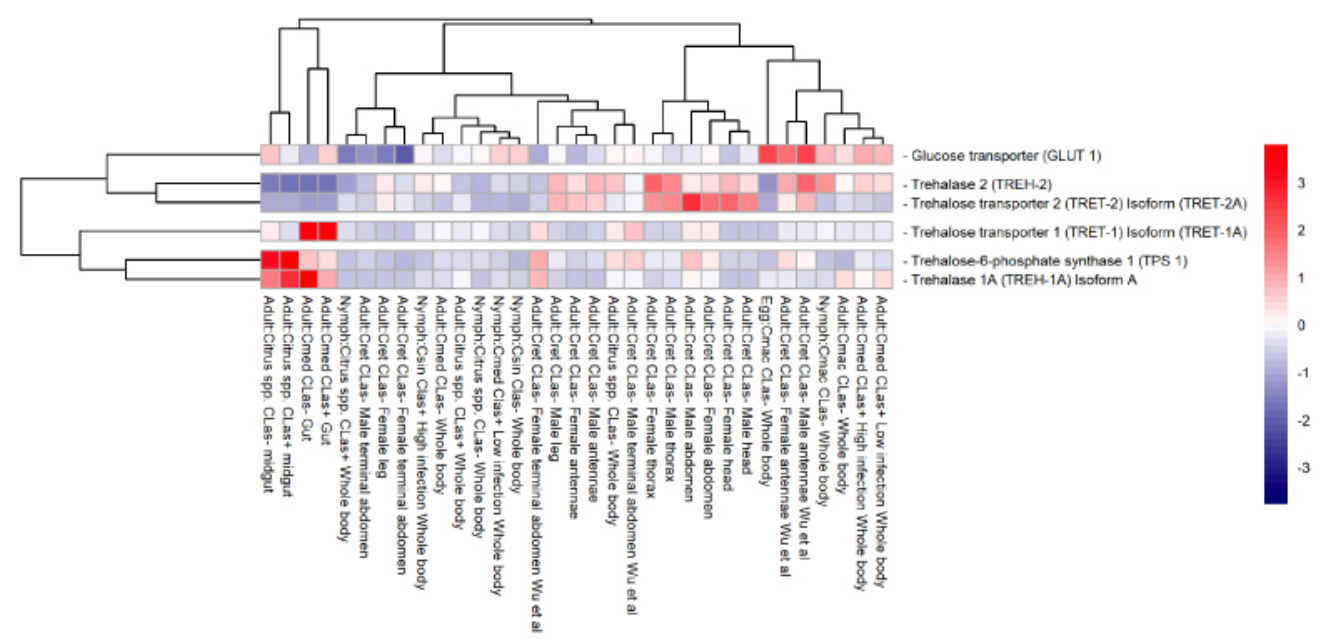

Figure 9. Comparison of RNA-seq datasets of genes involved in trehaloneogenesis. The heatmap shows results from $D$. citri reared on various citrus varieties, both infected and uninfected with $C$ Las. Expression values were collected from the Citrus Greening Expression Network [25]. Data in the heatmap show transcripts per million scaled by gene. RNA-seq data are available from NCBI Bioprojects PRJNA609978 and PRJNA448935 and published datasets [72]. Expression data for trehalose-6-phosphate synthase 2 (TPS 2), trehalase 2 (TREH-2), trehalose transporter 1 (TRET1) isoform (TRET1B), trehalose transporter 2 (TRET2) isoform (TRET2B), and trehalose transporter 2 (TRET2) isoform (TRET2C) are not present in the heatmap.

\section{CONCLUSION}

Manual annotation of the central metabolic pathways of glycolysis, gluconeogenesis, and trehaloneogenesis provides the accurate gene models required for development of molecular therapeutics to target $D$. citri. RNAi studies targeting genes involved in trehalose metabolism produced significant mortality in D. citri, [39, 88], demonstrating the functional application of the genes identified. Expression analysis of the genes annotated in carbohydrate metabolism pathways identified differences related to life stage, sex and tissue. Female insects preferentially feed on diets high in protein and males tend towards carbohydrate-rich diets [89-91]. Gene expression patterns reflect this dietary preference between males and females in A. gambiae, where males feeding entirely on sugar have elevated gene expression for carbohydrate metabolism [92]. A similar expression pattern was reported for $N$. lugens, where gene sets related to carbohydrate metabolism were upregulated in males compared with females [93]. Several of the carbohydrate metabolism genes in D. citri, including HK, PFK, aldolase, GAPDH-like 1, PGAM 1 and 2, PYK, enolase, PEPCK 1 and 2, aldose 1-epimerase, TPS 1, TREH1A and 2, and TRET1 and 2, show increased expression in various tissues in males than in females (results in [79]). Annotation of the carbohydrate metabolism genes advances the understanding of the basic biology of $D$. citri and will aid in the development of RNAi-based applications.

\section{REUSE POTENTIAL}

The manually curated gene models were annotated through a collaborative community project [11] to further understand psyllid biology and with a goal to annotate gene families related to immune response, metabolism and other major functions [94]. Continued examination of the glycolysis, gluconeogenesis, and trehaloneogenesis pathways across arthropods, and especially in insect vectors like $D$. citri, will provide novel and 
species-specific gene targets to control psyllid populations (potentially through RNAi) and reduce the effects of pathogens such as CLas.

\section{DATA AVAILABILITY}

The datasets supporting this article are available in the GigaScience GigaDB repository [79]. The gene models are part of an updated official gene set (OGS) for $D$. citri submitted to NCBI under Bioproject PRJNA29447. The OGS (v3) is also publicly available for download, BLAST analysis and expression profiling on Citrusgreening.org and the Citrus Greening Expression Network [25]. The $D$. citri genome assembly (v3), OGS (v3) and transcriptomes are accessible on the Citrusgreening.org portal [12]. Accession numbers for genes used in multiple alignments or phylogenetic trees are provided in Table 1.

\section{EDITOR'S NOTE}

This article is one of a series of Data Releases crediting the outputs of a student-focused and community-driven manual annotation project curating gene models and, if required, correcting assembly anomalies, for the Diaphorina citri genome project [95].

\section{DECLARATIONS}

\section{LIST OF ABBREVIATIONS}

ADP: adenosine diphosphate; Am: Apis mellifera; Ap: Acyrthosiphon pisum; ATP: adenosine triphosphate; CGEN: Citrus Greening Expression Network; CLas: Candidatus Liberibacter asiaticus; Cmac: Citrus macrophylla; Cmed: Citrus medica; Cret: Citrus reticulata; Csin: Citrus sinensis; Dc: Diaphorina citri; DHAP: dihydroxyacetone phosphate; Dm: Drosophila melanogaster; FBPase: fructose-1,6-bisphosphatase; GAP: glyceraldehyde-3-phosphate; GAPDH: glyceraldehyde 3-phosphate dehydrogenase; G6Pase/G6P: glucose-6-phosphatase; Hh: Halyomorpha halys; HK: hexokinase; Iso-seq: Isoform sequencing; MCOT: Maker, Cufflinks, Oases, Trinity; NCBI: National Center for Biotechnology Information; Nl: Nilaparvata lugens; $P C$ : pyruvate carboxylase; PEPCK: phosphoenolpyruvate carboxykinase; PFK: phosphofructokinase; PGAM: phosphoglycerate mutase; PGI: phosphoglucose isomerase; PGK: phosphoglycerate kinase; PYK: pyruvate kinase; RNAi: RNA interference; RNA-seq: RNA sequencing; Tc: Tribolium castaneum; TPI: triosephosphate isomerase; TPM: transcripts per million; TPP: trehalose-6-phosphate phosphatase; TPS: trehalose-6-phosphate synthase; TRE: trehalose; T6P: trehalose-6-phosphate.

\section{ETHICAL APPROVAL}

Not applicable.

\section{CONSENT FOR PUBLICATION}

Not applicable.

\section{COMPETING INTERESTS}

The authors declare that they have no competing interests.

\section{AUTHORS" CONTRIBUTIONS}

WBH, SJB, TD and LAM conceptualized the study; TD, SS, TDS and SJB supervised the study; SJB, TD, SS and LAM contributed to project administration; BT, AM, KK, CV, CM, DH and SA conducted investigation; PH, MF-G and SS contributed to software development; SS, TDS, JB 
PH and MF-G, developed methodology; SJB, TD, WBH and LAM acquired funding; BT, DLH, MRJ, AM and KK prepared and wrote the original draft; TD, SJB, SS, NP, TDS, WBH and JB reviewed and edited the draft.

\section{FUNDING}

This work was supported by USDA-NIFA grants 2015-70016-23028, HSI 2020-38422-32252 and 2020-70029-33199.

\section{ACKNOWLEDGEMENTS}

We would like to thank Helen Wiersma-Koch (Indian River State College) and Thomson Paris (USDA-ARS-Horticultural Research Laboratories) for assistance.

\section{REFERENCES}

1 Bové JM. Huanglongbing: a destructive, newly-emerging, century-old disease of citrus. J. Plant Pathol., 2006; 88: 7-37.

2 Haapalainen M. Biology and epidemics of Candidatus Liberibacter species, psyllid-transmitted plant-pathogenic bacteria. Ann. Appl. Biol., 2014; 165: 172-198.

3 Wang N, Pierson EA, Setubal JC et al. The Candidatus Liberibacter-host interface: insights into pathogenesis mechanisms and disease control. Annu. Rev. Phytopathol., 2017; 55: 451-482.

4 Wang N, Stelinski LL, Pelz-Stelinski KS et al. Tale of the Huanglongbing disease Pyramid in the context of the Citrus microbiome. Phytopathology, 2017; 107: 380-372.

5 Halbert SE, Manjunath KL. Asian citrus psyllids (Sternorrhyncha: Psyllidae) and greening disease of Citrus: a literature review and assessment of risk in Florida. Florida Entomol., 2004; 87: 330-353.

6 Hall DG, Richardson ML, Ammar E-D et al. Asian citrus psyllid, Diaphorina citri, vector of citrus Huanglongbing disease. Entomol. Exp. Appl., 2013; 146: 207-223.

7 Yamamoto PT, Fellipe MR, Sanches AL et al. Eficácia de Inseticidas para o Manejo de Diaphorina citri Kuwayama (Hemiptera: Psyllidae) em Citros. BioAssay, 2009; 4: 4.

8 Tiwari S, Mann RS, Rogers ME et al. Insecticide resistance in field populations of Asian citrus psyllid in Florida. Pest Manag. Sci., 2011; 67: 1258-1268.

9 Reese J, Christenson MK, Leng $\mathbf{N}$ et al. Characterization of the Asian citrus psyllid transcriptome. J. Genomics, 2014; 2: 54-82.

10 Saha S, Hosmani PS, Flores-Gonzalez M et al. Biocuration and improvement of the Diaphorina citri draft genome assembly with long reads, optical maps and long-range scaffolding. In: International Psyllid Annotation Consortium, Proceedings of 10th Arthropod Genomics Symposium, June 8, 2017; pp. $27-28$.

11 Saha S, Hosmani PS, Villalobos-Ayala K et al. Improved annotation of the insect vector of citrus greening disease: biocuration by a diverse genomics community. Database, 2019; 2019: baz035. doi:10.1093/database/baz035.

12 Citrus Greening Solutions. https://citrusgreening.org/. Accessed 24 September 2021.

13 Andrade EC, Hunter WB. RNAi feeding bioassay: development of a non-transgenic approach to control Asian citrus psyllid and other hemipterans. Entomol. Exp. Appl., 2017; 162: 389-396.

14 Ghosh SKB, Hunter WB, Park AL et al. Double strand RNA delivery system for plant-sap-feeding insects. PLoS One, 2017; 12: e0171861.

15 Ghosh SKB, Hunter WB, Park AL et al. Double-stranded RNA oral delivery methods to induce RNA interference in phloem and plant-sap-feeding Hemipteran insects. J. Vis. Exp., 2018; 4: 57390. doi:10.3791/57390.

16 Hunter WB, Sinisterra-Hunter XH. Chapter six - emerging RNA suppression technologies to protect citrus trees from citrus greening disease bacteria. Adv. Insect Physiol., 2018; 55: 163-197. doi:10.1016/bs.aiip.2018.08.001.

17 Killiny N, Kishk A. Delivery of dsRNA through topical feeding for RNA interference in the citrus sap piercing-sucking hemipteran, Diaphorina citri. Arch. Insect Biochem. Physiol., 2017; 95: e21394. 
18 Kishk A, Anber HAI, AbdEl-Raof TK et al. RNA interference of carboxyesterases causes nymph mortality in the Asian citrus psyllid, Diaphorina citri. Arch. Insect Biochem. Physiol., 2017; 94: e21377. doi:10.1002/arch.21377.

19 Yu X, Killiny N. RNA interference of two glutathione S-transferase genes, Diaphorina citri DcGSTe2 and DcGSTd1, increases the susceptibility of Asian citrus psyllid (Hemiptera: Liviidae) to the pesticides fenpropathrin and thiamethoxam. Pest Manag. Sci., 2018; 74: 638-647. doi:10.1002/ps.4747.

20 Hunter WB, Clarke S-KV, Mojica AFS et al. Advances in RNA suppression of the Asian citrus psyllid vector and bacteria (huanglongbing pathosystem). In: Stansly PA, Qureshi JA (eds), Asian Citrus Psyllid: Biology, Ecology and Management of the Huanglongbing Vector. Wallingford: CABI, 2020; pp. 258-284.

21 Yu H-Z, Huang Y-L, Lu Z-J et al. Inhibition of trehalase affects the trehalose and chitin metabolism pathways in Diaphorina citri (Hemiptera: Psyllidae). Insect Sci., 2021; 28: 718-734.

22 Sandoval-Mojica AF, Altman S, Hunter WB et al. Peptide conjugated morpholinos for management of the huanglongbing pathosystem. Pest Manag. Sci., 2020; 76: 3217-3224.

23 Hunter WB, Gonzalez MT, Tomich J. BAPC-assistedCRISPR/Cas9 system: targeted delivery into adult ovaries for heritable germline gene editing (Arthropoda: Hemiptera). bioRxiv. 2018; https://doi.org/10.1101/478743.

24 Hunter WB, Gonzalez MT, Tomich J. BAPC-assisted CRISPR-Cas9 delivery into nymphs and adults for heritable gene editing (Hemiptera). FASEB J., 2019; 33(Suppl 1): 626.2-626.2. doi:10.1096/fasebj.2019.33.1_supplement.626.2.

25 Flores-Gonzalez M, Hosmani PS, Fernandez-Pozo N et al. Citrusgreening.org: an open access and integrated systems biology portal for the Huanglongbing (HLB) disease complex. bioRxiv. 2019; https://doi.org/10.1101/868364.

26 Voet D, Voet JG, Pratt CW. Voet’s Principles of Biochemistry. Singapore: Wiley, 2018; pp. 478-523, Chapter 15 \& 16.

27 BioRender. 2022; https://biorender.com/. Accessed 1 June 2020.

28 Bretscher H, O’Connor MB. The role of muscle in insect energy homeostasis. Front. Physiol., 2020; 11: 580687.

29 Crabtree B, Newsholme EA. The activities of phosphorylase, hexokinase, phosphofructokinase, lactate dehydrogenase and the glycerol 3-phosphate dehydrogenases in muscles from vertebrates and invertebrates. Biochem. J., 1972; 126: 49-58.

30 Matsuda H, Yamada T, Yoshida M et al. Flies without trehalose. J. Biol. Chem., 2015; 290: 1244-1255.

31 Miyamoto T, Amrein H. Gluconeogenesis: an ancient biochemical pathway with a new twist. Fly, 2017; 11: $218-223$.

32 Becker A, Schlöder P, Steele JE et al. The regulation of trehalose metabolism in insects. Experientia, 1996; 52: 433-439.

33 Tournu H, Fiori A, Van Dijck P. Relevance of trehalose in pathogenicity: some general rules, yet many exceptions. PLoS Pathog., 2013; 9: e1003447.

34 Fraga A, Ribeiro L, Lobato $\mathbf{M}$ et al. Glycogen and glucose metabolism are essential for early embryonic development of the red flour beetle Tribolium castaneum. PLoS One, 2013; 8: e65125. doi:10.1371/journal.pone.0065125.

35 Miller D, Hannon C, Ganetzky B. A mutation in Drosophila Aldolase causes temperature-sensitive paralysis, shortened lifespan, and neurodegeneration. J. Neurogenet., 2012; 26: 317-327. doi:10.3109/01677063.2012.706346.

36 Wang WX, Li KL, Chen Y et al. Identification and function analysis of enolase Gene NlEno1 from Nilaparvata lugens (Stål) (Hemiptera: Delphacidae). J. Insect Sci., 2015; 15: 66. doi:10.1093/jisesa/iev046.

37 Ge LQ, Huang B, Li X et al. Silencing pyruvate kinase (NIPYK) leads to reduced fecundity in brown planthoppers, Nilaparvata lugens (Stål) (Hemiptera: Delphacidae). Arch. Insect Biochem. Physiol., 2017; 96: e21429. doi:10.1002/arch.21429.

38 Bartok O, Teesalu M, Ashwall-Fluss R et al. The transcription factor Cabut coordinates energy metabolism and the circadian clock in response to sugar sensing. EMBO J., 2015; 34: 1538-1553. doi:10.15252/embj.201591385.

39 Liu X, Zou Z, Zhang C et al. Knockdown of the trehalose-6-phosphate synthase gene using RNA interference inhibits synthesis of trehalose and increases lethality rate in Asian Citrus psyllid, Diaphorina citri (Hemiptera: Psyllidae). Insects, 2020; 11: 605. doi:10.3390/insects11090605. 
40 Chen J, Zhang D, Yao Q et al. Feeding-based RNA interference of a trehalose phosphate synthase gene in the brown planthopper, Nilaparvata lugens. Insect Mol. Biol., 2010; 19: 777-786.

41 Yang MM, Zhao LN, Shen QD et al. Knockdown of two trehalose-6-phosphate synthases severely affects chitin metabolism gene expression in the brown planthopper Nilaparvata lugens. Pest Manag. Sci., 2017; 73: 206-216.

42 Lu ZJ, Huang YL, Yu HZ et al. Silencing of the chitin synthase gene is lethal to the Asian citrus psyllid, Diaphorina citri. Int. J. Mol. Sci., 2019; 20: 3734.

43 Tang B, Wei P, Zhao LN et al. Knockdown of five trehalase genes using RNA interference regulates the gene expression of the chitin biosynthesis pathway in Tribolium castaneum. BMC Genom., 2016; $16: 67$.

44 Zhang L, Qiu LY, Yang HL et al. Study on the effect of wing bud chitin metabolism and its developmental network genes in the brown planthopper, Nilaparvata lugens, by knockdown of TRE gene. Front. Physiol., 2017; 8: 750.

45 Zhao LN, Yang MM, Shen QD et al. Functional characterization of three trehalase genes regulating the chitin metabolism pathway in rice brown planthopper using RNA interference. Sci. Rep., 2016; 6: 27841.

46 Yu XD, Gowda S, Killiny N. Double-stranded RNA delivery through soaking mediates silencing of the muscle protein 20 and increases mortality to the Asian citrus psyllid, Diaphorina citri. Pest Manag. Sci., 2017; 73: 1846-1853.

47 Santos-Ortega Y, Killiny N. Silencing of sucrose hydrolase causes nymph mortality and disturbs adult osmotic homepstasis in Diaphorina citri (Hemiptera: Liviidae). Insect Biochem. Mol. Biol., 2018; 101: 131-143.

48 Miller S, Tamayo B, Shippy TD et al. Annotation of chitin biosynthesis genes in Diaphorina citri, the Asian citrus psyllid. Gigabyte, 2021; 1: https://doi.org/10.46471/gigabyte.23.

49 Hunter WB, Gonzalez MT, Andrade EC. Double stranded RNA compositions for reducing Asian citrus psyllid infestation and methods of use. US Patent. 2017; https://patentimages.storage.googleapis.com/5c/19/bc/a3f03f405af2e2/US20170211082A1.pdf.

50 Bachman P, Fischer J, Song $\mathbf{Z}$ et al. Environmental fate and dissipation of applied dsRNA in soil, aquatic systems, and plants. Front. Plant Sci., 2020; 11: 21.

51 Christiaens 0, Whyard S, Vélez AM et al. Double-stranded RNA technology to control insect pests: current status and challenges. Front. Plant Sci., 2020; 11: 451.

52 Fletcher SJ, Reeves PT, Hoang BT et al. A perspective on RNAi-based biopesticides. Front. Plant Sci., 2020; 11: 51.

53 Kunte N, McGraw E, Bell S et al. Prospects, challenges and current status of RNAi through insect feeding. Pest Manag. Sci., 2020; 76: 26-41.

54 Raybould A, Burns A. Problem formulation for off-target effects of externally applied double-stranded RNA-based products for pest control. Front. Plant Sci., 2020; 11: 424.

55 Hosmani PS, Shippy T, Miller S et al. A quick guide for student-driven community genome annotation. PLoS Comput. Biol., 2019; 15: e1006682.

56 National Center for Biotechnology Information. NCBI protein database. https://www.ncbi.nlm.nih.gov/protein. Accessed 24 September 2021.

57 Hosmani PS, Flores-Gonzalez M, Shippy T et al. Chromosomal length reference assembly for Diaphorina citri using single-molecule sequencing and Hi-C proximity ligation with manually curated genes in developmental, structural and immune pathways. bioRxiv. 2019; https://doi.org/10.1101/869685.

58 Shippy TD, Miller S, Massimino C et al. Annotating genes in Diaphorina citri genome version 3. protocols.io. 2020; http://dx.doi.org/10.17504/protocols.io.bniimcce.

59 Kumar S, Stecher G, Tamura K. MEGA7: molecular evolutionary genetics analysis version 7.0 for bigger datasets. Mol. Biol. Evol., 2016; 33: 1870-1874. doi:10.1093/molbev/msw054.

60 Thurmond J, Goodman JL, Strelets VB et al. FlyBase 2.0: the next generation. Nucleic Acids Res., 2019; 47: D759-D765.

61 Richards S, Gibbs RA et al. Tribolium Genome Sequencing Consortium. The genome of the model beetle and pest Tribolium castaneum. Nature, 2008; 452: 949-955.

62 Elsik CG, Worley KC, Bennett AK et al. Finding the missing honey bee genes: lessons learned from a genome upgrade. BMC Genom., 2014; 15: 86. 
63 International Aphid Genomics Consortium. Genome sequence of the pea aphid Acyrthosiphon pisum. PLoS Biol., 2010; 8: e1000313.

64 Xue J, Zhou X, Zhang C-X et al. Genomes of the rice pest brown planthopper and its endosymbionts reveal complex complementary contributions for host adaptation. Genome Biol., 2014; 15: 521.

$65 \mathrm{Ma} \mathrm{W}, \mathrm{Xu}$ L, Hua $\mathrm{H}$ et al. Chromosomal-level genomes of three rice planthoppers provide new insights into sex chromosome evolution. Mol. Ecol. Resour., 2021; 21: 226-237.

66 Sparks ME, Bansal R, Benoit JB et al. Brown marmorated stink bug, Halyomorpha halys (Stål), genome: putative underpinnings of polyphagy, insecticide resistance potential and biology of a top worldwide pest. BMC Genom., 2020; 21: 227.

67 Kriventseva EV, Kuznetsov D, Tegenfeldt F et al. OrthoDB v10: sampling the diversity of animal, plant, fungal, protist, bacterial and viral genomes for evolutionary and functional annotations of orthologs. Nucleic Acids Res., 2019; 47: D807-D811.

68 Larkin A, Marygold SJ, Antonazzo G et al. FlyBase: updates to the Drosophila melanogaster knowledge base. Nucleic Acids Res., 2021; 49: D899-D907.

69 Nation JL Sr. Insect Physiology and Biochemistry. 3rd ed, Boca Raton: CRC Press, 2015; pp. 223-249, Chapter 8.

70 Adams MD, Celniker SE, Holt RA. The genome sequence of Drosophila melanogaster. Science, 2000; 287: 2185-2195. doi:10.1126/science.287.5461.2185.

71 Duvernell DD, Eanes WF. Contrasting molecular population genetics of four hexokinases in Drosophila melanogaster, D. simulans and D. yakuba. Genetics, 2000; 156: 1191-1201.

72 Wu Z, Zhang H, Bin S et al. Antennal and abdominal transcriptomes reveal chemosensory genes in the Asian citrus psyllid, Diaphorina citri. PLoS One, 11: e01593722016.

73 Kruse A, Fattah-Hosseini S, Saha S et al. Combining 'omics and microscopy to visualize interactions between the Asian citrus psyllid vector and the Huanglongbing pathogen Candidatus Liberibacter asiaticus in the insect gut. PLoS One, 2017; 12: e0179531. doi:10.1371/journal.pone.0179531.

74 Vyas M, Fisher TW, He R et al. Asian citrus psyllid expression profiles suggest Candidatus Liberibacter Asiaticus-mediated alteration of adult nutrition and metabolism, and of nymphal development and immunity. PLoS One, 2015; 10: e0130328. doi:10.1371/journal.pone.0130328.

75 Yu H-Z, Li N-Y, Zeng X-D et al. Transcriptome analyses of Diaphorina citri midgut responses to Candidatus Liberibacter Asiaticus infection. Insects, 2020; 11: 171. doi:10.3390/insects11030171.

76 Mordue W, Goldsworthy GJ, Brady J et al. Insect Physiology. Blackwell, 1980. ISBN: 9780632003853.

77 Currie PD, Sullivan DT. Structure and expression of the gene encoding phosphofructokinase (PFK) in Drosophila melanogaster. J. Biol. Chem., 1994; 269: 24679-24687.

78 O'Brien SJ, MacIntyre RJ. Genetics and biochemistry of enzymes and specific proteins of Drosophila. In: Ashburner M, Wright TRF (eds), Genetics and Biology of Drosophila. vol. 2a, Academic Press, 1978. ISBN: $9780120649402,0120649403$.

79 Tamayo B, Kercher K, Vosburg C et al. Supporting data for "Annotation of glycolysis, gluconeogenesis, and trehaloneogenesis pathways provide insight into carbohydrate metabolism in the Asian citrus psyllid”. GigaScience Database. 2022; http://dx.doi.org/10.5524/100996.

80 Takeda K, Komuro Y, Hayakawa T et al. Mitochondrial phosphoglycerate mutase 5 uses alternate catalytic activity as a protein serine/threonine phosphatase to activate ASK1. Proc. Natl Acad. Sci. USA, 2009; 106: 12301-12305.

81 Wang W-X, Li K, Chen Y et al. Identification and function analysis of enolase gene NlEno1 from Nilaparvata lugens (Stal) (Hemiptera: Delphacidae). J. Insect Sci., 2015; 15: 66. doi:10.1093/jisesa/iev046.

82 Pan B-Y, Li G-Y, Wu Y et al. Glucose utilization in the regulation of chitin synthesis in Brown Planthopper. J. Insect Sci., 2019; 19: 3. doi:10.1093/jisesa/iez081.

83 Elbein AD, Pan YT, Pastuszak I et al. New insights on trehalose: a multifunctional molecule. Glycobiology, 2003; 13: 17R-27R.

84 Shukla E, Thorat LJ, Nath BB et al. Insect trehalase: physiological significance and potential applications. Glycobiology, 2015; 25: 357-367.

85 Tang B, Wang S, Wang S-G et al. Invertebrate trehalose-6-phosphate synthase gene: genetic architecture, biochemistry, physiological function, and potential applications. Front. Physiol., 2018; 9: 30 . 
86 Tang B, Xu Q, Zhao L et al. Progress in research on the characteristics and functions of trehalose and the TPS gene in insects. Chin. J. Appl. Entomol., 2014; 51: 1397-1405.

87 Yoshida M, Matsuda H, Kubo H et al. Molecular characterization of Tps1 and Treh genes in Drosophila and their role in body water homeostasis. Sci. Rep., 2016; 6: 30582.

88 Hunter WB, Wintermantel WM. Optimizing efficient RNAi-mediated control of hemipteran pests (psyllids, leafhoppers, whitefly): modified pyrimidines in dsRNA triggers. Plants, 2021; 10: 1782.

89 Camus MF, Piper MDW, Reuter M. Sex-specific transcriptomic responses to changes in the nutritional environment. Elife, 2019; 8: e47262.

90 Corrales-Carvajal VM, Faisal AA, Ribeiro C. Internal states drive nutrient homeostasis by modulating exploration-exploitation trade-off. Elife, 2016; 5: e19920. doi:10.7554/eLife.19920.

91 Lee KP, Simpson SJ, Clissold FJ et al. Lifespan and reproduction in drosophila: new insights from nutritional geometry. Proc. Natl Acad. Sci. USA, 2008; 105(7): 2498-2503. doi:10.1073/pnas.0710787105.

92 Baker DA, Nolan T, Fischer B et al. A comprehensive gene expression atlas of sex- and tissue-specificity in the malaria vector, Anopheles gambiae. BMC Genom., 2011; 12: 296. doi:10.1186/1471-2164-12-296.

93 Xue J, Bao YY, Li Bl et al. Transcriptome analysis of the brown planthopper Nilaparvata lugens. PLoS One, 2010; 5: e14233. doi:10.1371/journal.pone.0014233.

94 Citrus Greening Solutions. Annotation of psyllid genome. https://citrusgreening.org/annotation/index. Accessed 24 September 2021.

95 Asian citrus psyllid community annotation series. GigaByte. 2022; https://doi.org/10.46471/GIGABYTE_SERIES_0001. 